Julia Fleck, Peter Griebel, Adam M. Steinberg, Christoph M. Arndt, Clemens Naumann, Manfred Aigner, Autoignition of Hydrogen / Nitrogen Jets in Vitiated Air Crossflows at Different Pressures, Proceedings of the Combustion Institute 34 (2013) 3185-3192.

The original publication is available at www.elsevier.com

http://dx.doi.org/10.1016/j.proci.2012.05.039 


\title{
AUTOIGNITION OF HYDROGEN / NITROGEN JETS IN VITIATED AIR CROSSFLOWS AT DIFFERENT PRESSURES
}

Julia M. Fleck ${ }^{1}$, Peter Griebel ${ }^{1}$, Adam M. Steinberg ${ }^{2}$, Christoph M. Arndt ${ }^{1}$, Clemens Naumann ${ }^{1}$, Manfred Aigner ${ }^{1}$

${ }^{1}$ German Aerospace Center (DLR), Institute of Combustion Technology, Pfaffenwaldring 38-40, 70569 Stuttgart, Germany

${ }^{2}$ University of Toronto, Institute for Aerospace Studies, 4925 Dufferin Street, Toronto, Canada M3G 5T6

\author{
Corresponding Author Contact Information: \\ German Aerospace Center (DLR) \\ Julia M. Fleck \\ Institute of Combustion Technology \\ Pfaffenwaldring 38-40, 70569 Stuttgart, Germany \\ Phone: +49 7116862640 \\ Fax: +49 7116862578 \\ Email: Julia.Fleck@dlr.de
}




\begin{abstract}
Autoignition of hydrogen/nitrogen jets in crossflows of vitiated air has been experimentally studied at conditions relevant for gas turbine combustor operation, including practical pressures (5, 10, 15 bar), crossflow temperatures $\left(T_{c f}=1185 \mathrm{~K}\right.$ and $\left.1143 \mathrm{~K}\right)$, crossflow velocities $\left(\mathrm{u}_{\mathrm{cf}}=200\right.$ and $300 \mathrm{~m} / \mathrm{s}$ ), and jet momentum ranges. Experiments were performed in an optically accessible duct, in which the appearance of autoignition events was investigated using high-speed imaging. At the different crossflow parameters, the $\mathrm{H}_{2}$ mole fraction $\mathrm{X}_{\mathrm{H} 2}$ in the fuel jet was incrementally increased until autoignition created a stable flame. During this process, the autoignition kernel and subsequent flame dynamics were recorded at a rate of $30 \mathrm{kHz}$. In order to compare the experimental autoignition characteristics of the partially premixed, turbulent system to a homogeneous system, kinetic simulations of homogenous systems were conducted for pressures, temperatures, and vitiated air compositions corresponding to the experiments. The ignition delay times estimated from the experiment were considerably shorter than those from the kinetic simulations, and exhibited a different pressure dependency. These differences suggest that, in the current flow configuration, autoignition is strongly affected by turbulent mixing and flow field characteristics.
\end{abstract}

\title{
Keywords
}

Autoigntion, Hydrogen, Jet in Crossflow 


\section{Introduction}

Detailed understanding of autoignition in reactive mixtures is becoming increasingly relevant for modern low- $\mathrm{NO}_{\mathrm{x}}$ combustion technologies, such as lean premixed combustion (LPC) systems in stationary gas turbines (GT) [1], HCCI engines [2], and high speed propulsion devices [3]. In LPC systems, unwanted autoignition in mixing zones can lead to combustor damage. This issue becomes even more problematic if highly reactive hydrogen rich fuels, such as syngases, are to be used since they exhibit a higher propensity to autoignite compared to conventional GT fuels, such as natural gas, at relevant operating conditions [4].

Autoignition in technical applications is a highly complex process, involving turbulent mixing and fluid dynamics, in addition to normal autoignition chemistry. This means that the ignition process is not only a function of local temperature, pressure, and composition, but is also affected by fluid-dynamic strain-rate, mixing, and the turbulence intensity. A number of autoignition studies with hydrogen in non-premixed configurations have provided valuable understanding of the nature of autoignition and the influencing parameters. Kreutz and Law [5] found that ignition appeared as localized kernels near the location of maximum temperature. This is in agreement with the finding of Mastorakos et al., who showed that autoignition preferentially occurs at the most reactive mixture fraction [6]. This depends on the operating conditions and is expected on the fuel lean side for $\mathrm{H}_{2}$ [7]. Moderate turbulence intensities have been found to facilitate ignition, while increased strain rates and high turbulence intensities were found to have an inhibiting effect [8-10]. A recent review of nonpremixed autoignition is given by Mastorakos [7].

However, the autoignition process is far from being completely understood, and further research is needed in turbulent non-premixed and partially premixed configurations. One feature of particular interest for hydrogen is its complex autoignition pressure dependence. This is due to different preferential reaction pathways in different pressure and temperature 
ranges, leading to the so called hydrogen ignition limits [5, 11-12]. Since technical systems commonly operate at elevated pressure, the pressure influence on autoignition in technically relevant combustors using hydrogen rich fuels is of high interest.

In the present study, autoignition that initiates stable combustion of hydrogen $\left(\mathrm{H}_{2}\right) /$ nitrogen $\left(\mathrm{N}_{2}\right)$ jets in a crossflow of vitiated air was experimentally investigated at 5, 10 and 15 bar using high-speed imaging. Additionally, chemical kinetic calculations were conducted on a homogenous system at the experimental conditions in order to compare the overall trends and the ignition delay times of an idealised system with the technical system.

The jet-in-crossflow (JICF) configuration studied here finds applications in an array of engineering problems and therefore has been studied extensively over the past years in nonreacting and reacting flows [3, 13-16]. JICFs exhibit highly strained regions of non-uniform mixing, reaction rate, and temperature, and therefore mimic conditions of technical relevance. The chosen operating conditions, having high crossflow temperatures (1143 and $1185 \mathrm{~K}$ ) and velocities (200 and $300 \mathrm{~m} / \mathrm{s}$ ), along with the fuel jet being injected into vitiated air, are in the range which is relevant for mixing sections of gas turbine reheat combustors $[1,17-18]$.

\section{Experimental Set-up and Methodology}

\section{$\underline{2.1 \mathrm{JICF} \text { test-section }}$}

The experiments were performed in a $25 \times 25 \mathrm{~mm}^{2}$ cross section square duct, which was optically accessible from all four sides and installed in a high-pressure combustion test rig. The pressure casing was equipped with large quartz glass windows providing optical access to the duct. When inserted into the pressure casing, the field of view ranged from about $40 \mathrm{~mm}$ upstream to $74 \mathrm{~mm}$ downstream of the fuel injector (FI) (see Fig. 1) in x-direction and +/- 9 $\mathrm{mm}$ in y-direction. The fuel jet was injected from the lower wall into a crossflow of vitiated air, through a circular fuel injector with an inner diameter of $d_{\mathrm{FI}}=5.6 \mathrm{~mm}$. Minimal cooling 
and thermal barrier coatings were used to limit the overall heat loss in the duct, which was about $6 \%$. The conditions in the duct have been measured with respect to vertical temperature profiles, velocity fields and vitiated air composition in a previous study [19].

The vitiated air was generated by a slightly modified FLOX ${ }^{\circledR}$ burner [20], which was operated with natural gas at fuel lean conditions $(0.43<\Phi<0.47$, depending on operating pressure). To match a desired oxygen content in the vitiated air of around $\mathrm{X}_{\mathrm{O} 2}=0.15$, simultaneously with the desired duct inflow temperature, the exhaust gas was diluted with additional air before entering the duct. The highest total mass flow rate of the vitiated air was $865 \mathrm{~g} / \mathrm{s}$. The composition was calculated from $\mathrm{X}_{\mathrm{O} 2}$ that was measured $178 \mathrm{~mm}$ upstream of the of the fuel injector using paramagnetism (Magnos 16), and varied slightly for different operating conditions. Table 1 summarizes the composition of the vitiated air for the lowest and highest measured $\mathrm{O}_{2}$ contents. Further details of the experimental test-section can be found in [1].

\subsection{Operating conditions and measuring procedure}

The experiments were performed at three different pressures (5, 10, 15 bar). For each pressure, three different test cases were carried out (see Table 2), each with a constant crossflow temperature $\left(\mathrm{T}_{\mathrm{cf}}\right)$ and velocity $\left(\mathrm{u}_{\mathrm{cf}}\right)$. The crossflow pressure and temperature were monitored during every experiment at a rate of $1 \mathrm{~Hz}$, and the crossflow velocity was calculated from these values and the mass flow rate. The pressure was measured with a pressure transducer in the inlet of the duct, $195 \mathrm{~mm}$ upstream of the fuel injector. The crossflow temperature was monitored by means of a thermocouple probe (TC-1, type K) at the axis of symmetry (y=0 mm), which was permanently installed $110 \mathrm{~mm}$ upstream of the fuel injector in the upper channel wall and was shielded with a ceramic casing to minimize radiative heat loss. 
For each pressure/temperature/velocity condition, two $\mathrm{H}_{2} / \mathrm{N}_{2}$ fuel jet compositions were studied, with a target set point mole fraction of $\mathrm{X}_{\mathrm{H} 2}$ in $\mathrm{N}_{2}=0.64$ (Mix1) or 0.52 (Mix2). However, autoignition leading to a stable flame in the duct usually occurred at lower $\mathrm{X}_{\mathrm{H} 2}$ than the targeted set point value, as will be discussed below. For all cases, the jet was injected into the crossflow at a $90^{\circ}$ angle. The jet temperature, which was measured in the feed pipe about $40 \mathrm{~mm}$ upstream of the fuel injector, was $300 \pm 12 \mathrm{~K}$. The set point equivalence ratio for perfect premixing of the jet and crossflow was $\Phi=0.4$, resulting in a maximum thermal load of $855 \mathrm{~kW}$. At these conditions, the target set point jet-to-crossflow momentum flux ratios were $\mathrm{J}=2.4$ and 4.7 for Mix1 and 2, respectively, resulting in two different jet penetration depths and mixing behaviors [15].

The measuring procedure was as follows. At constant crossflow conditions, the $\mathrm{N}_{2}$ mass flow rate in the jet was adjusted to its set point value corresponding to the targeted fuel composition (Mix1 or Mix2). Then, the $\mathrm{H}_{2}$ mass flow rate was incrementally increased in steps of $0.05 \mathrm{~g} / \mathrm{s}$ (5 bar) or $0.1 \mathrm{~g} / \mathrm{s}(10,15 \mathrm{bar})$, thereby stepwise increasing $\mathrm{X}_{\mathrm{H} 2}$ in the fuel and the overall equivalence ratio. Each level was held for a minimum of $15 \mathrm{~s}$. At some $\mathrm{H}_{2}$ flow rate, autoignition created a stable flame in the duct. As soon as this occurred, a high-speed camera, which was operated in the post-triggering mode (described below), was triggered to capture the ignition and stabilization event. The fuel was then shut down to avoid hardware damage from thermal stresses.

A rise in both pressure and temperature was observed during flame-stabilizing autoignition, as described in Ref. [1]. This is likely due to the thermal expansion and stronger jet penetration associated with the burning jet that occurred rapidly after the onset of autoignition [21]. As in Ref. [1], the conditions in the duct ( $p, \mathrm{~T}_{\mathrm{cf}}, \mathrm{X}_{\mathrm{H} 2}$ ) at flame stabilization were defined to be those at the measurement immediately prior to the rise in temperature and pressure. For different measuring points, the instantaneous crossflow temperature at a stabilizing autoignition event 
differed from the set point value $\left(\mathrm{T}_{\mathrm{cf}}\right)$ by a maximum of $1.1 \%$. This deviation resulted from the day-to-day reproducibility and the operational standard deviation at steady-state conditions, which were up to $1.3 \%$. The difference between the instantaneous pressure and the set point value was up to $1.8 \%$ at 10 and 15 bar, and up to $6.6 \%$ at 5 bar. This is mainly related to a slight pressure drift during the autoignition experiments, which arose since the automated pressure control system had to be deactivated to avoid over-control problems caused by the slow response time of the flow system.

\subsection{High-speed imaging}

In order to visualize autoignition and flame stabilization in the duct, the broadband luminosity was recorded with a high-speed camera (LaVision HSS6) from the side, detecting light emission in the visible wavelength range. The camera was equipped with a commercial objective lens (Nikkor), having a focal length of $85 \mathrm{~mm}$ and operated at f/1.4. Images were recorded at a frame rate of $30 \mathrm{kHz}$, with a sensor resolution of 640 x 376 pixels resulting in a spatial resolution of $0.16 \mathrm{~mm} /$ pixel. The camera was operated in the post-triggering mode, wherein images are taken continuously until a trigger signal is received. At the moment of triggering, images from about $0.7 \mathrm{~s}$ before the trigger signal were recorded. The camera was manually triggered immediately after flame stabilization in the duct, allowing the development of the autoignition induced flame to be captured.

\section{Kinetic Simulations}

Chemical kinetics simulations of homogenous systems representing the experimental conditions were performed using CHEMKIN II to elucidate the purely chemical kinetics effects. The composition of the vitiated air flowing into the duct was modeled with a Perfectly

Stirred Reactor/Plug Flow Reactor sequence (PSR/PFR), simulating the natural gas 
combustion at lean conditions and subsequent addition of dilution air and heat loss. This resulted in a modeled vitiated air composition that reproduced the experimentally determined composition. The autoignition reaction system was then initialized in a PFR with an admixture of the fuel blend. The ignition delay time was determined from the maximum temperature gradient $\left(\tau_{\text {ign }}=\mathrm{t}\left(\left[\mathrm{dT} \mathrm{T}_{\mathrm{hr}} / \mathrm{dt}\right]_{\max }\right)\right)$. The calculations of the kinetic system used the RDv06-NGQ reaction mechanism, which for the $\mathrm{H}_{2}$-subsystem is based on the mechanism of Li et al. [22] and was validated inter alia by Herzler et al. [12] and Keromnes et al. [23].

\section{Results}

\section{$\underline{4.1 \text { General appearance of autoignition }}$}

The general autoignition and flame stabilization characteristics observed from the high-speed images were comparable to Ref. [1] at all investigated pressures. In agreement with the literature, autoignition appeared as distinct, spatially distributed kernels [5, 9] (see Fig. 2, $\mathrm{t}=$ 0.00 ms; Case A15, Mix2). Figure 3 shows typical initial positions of detected ignition kernels for the different pressures, taken from Case A, Mix2 conditions. The axial positions of the kernels are derived from their upstream leading edge, while the y-positions are defined using the kernel centroid. Each different marker shape represents one measurement sequence during which autoignition occurred. Markers of the same shape indicate different autoignition kernels that occurred during the same measurement sequence. The upper image in Fig. 3 (p = 15 bar $)$ is overlaid with a mean flow pattern taken from an experiment with $\mathrm{J}=3.5\left(\mathrm{u}_{\mathrm{cf}}=200\right.$ $\mathrm{m} / \mathrm{s}, \mathrm{p}=15 \mathrm{bar}$ ), which is approximately the value for Case $\mathrm{A}$ [1]. The dotted lines are $\mathrm{u}_{\mathrm{x}} / \mathrm{u}_{\mathrm{cf}}$ isolines, which are expected to be similar to Case $\mathrm{A}$ as $\mathrm{u}_{\mathrm{x}} / \mathrm{u}_{\mathrm{cf}}$ is primarily a function of $\mathrm{J}$ and $\mathrm{d}_{\mathrm{FI}}$ [24]. The solid line is the jet trajectory defined based on the maximum velocity.

Prior to flame stabilization, so called "non-stabilizing kernels" were detected in most cases. These kernels convected out of the duct without initiating a stable flame. In the current study, 
these kernels were distributed over an axial range from $\mathrm{x} \approx 15 \mathrm{~mm}$ (considering all cases) up to the end of the optically accessible part of the duct. The "flame-stabilizing kernels" were defined to be kernels that propagated upstream and ignited the entire jet, as shown in Fig. 2 (t $=0.00-0.43 \mathrm{~ms})$. Generally, these kernels initiated in an axial range of $\mathrm{x} \approx 13-40 \mathrm{~mm}$. The axial ranges of stabilizing and non-stabilizing kernels in Fig. 3 also are representative for Mix1 and Mix2 at all conducted test cases. The reason that flame-stabilizing kernels occurred in this x-range is likely related to a low velocity region in the jet wake, which allowed the flame to propagate against the flow [1]. The broad range where ignition kernels originated and the overlap of regions with flame-stabilizing and non-stabilizing kernels are due to the strong dependence of autoignition on the local strain, temperature, and mixture fraction histories of specific fluid parcels. In the current configuration, these fluid parcels are influenced by random turbulent fluctuations and coherent vortex shedding and motion of the jet $[7,25]$. In addition, the experimental temperature deviation contributes to the distribution, since the ignition kernel location was found to be strongly dependent on the temperature [10].

\subsection{Pressure dependence of jet autoignition}

In order to visualize the dependence of jet autoignition on pressure, Fig. 4 shows $\mathrm{X}_{\mathrm{H} 2}$ for flame-stabilizing autoignition events, $\mathrm{X}_{\mathrm{H} 2, \mathrm{fs}}$, over the conducted parameter variations. In addition, the corresponding mean values of each test case are indicated. These also are summarized in Table 3, along with the instantaneous mean momentum flux ratios at ignition.

Differences were observed in $\mathrm{X}_{\mathrm{H} 2 \text {,fs }}$ for the different pressures. These differences also depended on the duct inlet conditions. For Case A, doubling the pressure from 5 to 10 bar did not cause a significant change in $\mathrm{X}_{\mathrm{H} 2 \text {,fs }}$ for either Mix1 or Mix2. When further increasing the pressure by $50 \%$ from 10 to 15 bar, $\mathrm{X}_{\mathrm{H} 2 \text {,fs }}$ increased from $0.27-0.3$ to around 0.5 . 
Temperature also had a major effect. Autoignition for Case B, which had a 42 K lower crossflow temperature compared to Cases $A$ and $C$, was shifted to significantly higher $\mathrm{X}_{\mathrm{H} 2 \text {,fs, }}$, greater than 0.45 , for all pressures. This is expected since the temperature is a dominant factor influencing the kinetic ignition delay time. Similar sensitivity of autoignition to temperature was also found in other studies in non-premixed configurations [10].

Aside from the influence of temperature, the observed qualitative behavior with pressure for Case B with Mix2 (higher jet penetration) was similar to Case A, with an increase in pressure

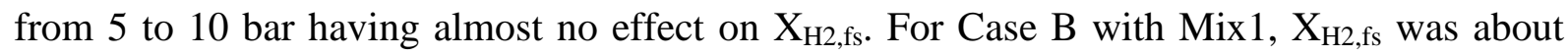
0.15 higher at 10 bar compared to 5 bar. For both mixes, further increasing the pressure from 10 to 15 bar increased $\mathrm{X}_{\mathrm{H} 2 \text {,fs }}$ to the extent that the target set point could be reached without ignition initiating a stable flame (Mix1: 0.64, Mix2: $0.52 \mathrm{X}_{\mathrm{H} 2}$ in $\mathrm{N}_{2}$ ).

A considerably different pressure dependence was found in Case C, which had a crossflow velocity reduced by $100 \mathrm{~m} / \mathrm{s}$ relative to Cases $\mathrm{A}$ and $\mathrm{B}$. Again, $\mathrm{X}_{\mathrm{H} 2 \text {,fs }}$ for 5 and 10 bar were at a comparable level of around 0.21-0.27 for both Mix1 and Mix2. This is slightly lower than for Case A, which is likely related to the increased residence times due to the lower crossflow velocities. However, no increase in $\mathrm{X}_{\mathrm{H} 2, \mathrm{fs}}$ was observed at a pressure of 15 bar.

\subsection{Ignition delay times}

The results described above can be interpreted as representing the relationship between the fuel jet $\mathrm{H}_{2}$ content and the operating parameters that yields a sufficiently short ignition delay time $\left(\tau_{\text {ign }}\right)$ to generate autoignition kernels in the appropriate axial region resulting in ignition of a stable flame. That is, a stable flame could develop once $\tau_{\text {ign }}$ was short enough for ignition events to occur in a range of $\mathrm{x} \approx 13$ - $40 \mathrm{~mm}$. Generally, these flame-stabilizing kernels were the most upstream ones in a captured measurement sequence; they exhibited the minimum $\tau_{\text {ign }}$ for a given case (shorter than $\tau_{\text {ign }}$ of the non-stabilizing kernels). 
Hence, the range of critical experimental ignition delay times leading to flame stabilization in the duct ( $\left.\tau_{\text {exp,crit }}\right)$ was roughly estimated from the $\mathrm{x}$-range of the flame stabilizing autoignition kernels and the crossflow bulk velocity. For Cases A and B $\left(\mathrm{u}_{\mathrm{cf}}=300 \mathrm{~m} / \mathrm{s}\right)$, the estimated range was $\tau_{\text {exp,crit }}=0.04-0.13 \mathrm{~ms}$. For Case $\mathrm{C}\left(\mathrm{u}_{\mathrm{cf}}=200 \mathrm{~m} / \mathrm{s}\right) \tau_{\text {exp,crit }}=0.065-0.2 \mathrm{~ms}$. That is, the lower velocities lead to slightly longer ignition delay times. However, the ranges overlap due to the considerable scatter of ignition kernel locations.

Of course, this method yields only a rough, likely underestimated, minimum ignition delay time since the exact delay time is related to a fluid parcel traveling along a trajectory subjected to varying local mean velocities and velocity fluctuations. It is, however, a reference value to compare to the simulated ignition delay times.

\section{$\underline{4.4 \text { Kinetic simulations }}$}

In order to investigate the chemical kinetic behavior at conditions corresponding to the experiment, simulations of homogeneous systems were carried out for a range of fuel $\mathrm{H}_{2} / \mathrm{N}_{2}$ ratios in vitiated air at $\mathrm{p}=5,10$, and 15 bar and $\mathrm{T}_{\text {fuel }}=303 \mathrm{~K}$. The temperature used for the vitiated air was $1173 \mathrm{~K}$, which is within the experimental temperature range of Cases A and C. For each $\mathrm{X}_{\mathrm{H} 2}$, the equivalence ratio was varied, thus representing different mixing states present in the JICF.

Figure 5 shows the dependence of the computed ignition delay time on the mixture state, represented by $\Phi$, for $\mathrm{p}=5,10$, and 15 bar and different $\mathrm{X}_{\mathrm{H} 2}$. At all pressures, it was observed that increasing $\mathrm{X}_{\mathrm{H} 2}$ decreased $\tau_{\text {ign }}$, but that this effect is less significant at lower equivalence ratios. Further, at a given $\Phi$, the decrease in $\tau_{\text {ign }}$ is more pronounced between $\mathrm{X}_{\mathrm{H} 2}=0.3$ and 0.5 than between 0.5 and 0.7 . For the higher $\mathrm{X}_{\mathrm{H} 2}(0.5$ and 0.7$), \tau_{\mathrm{ign}}$ exhibits a minimum at $\Phi \approx$ 0.15 (5 bar) or $\Phi \approx 0.1(10,15$ bar). Comparing the different pressures reveals that for about 
$\Phi<0.25, \tau_{\text {ign }}$ of 5 bar is up to one order of magnitude smaller than of 10 and 15 bar. In contrast, $\tau_{\text {ign }}$ for 10 bar is only slightly shorter than for 15 bar for $\Phi<0.2$.

The described tendencies are related to the parameters that change with $\mathrm{X}_{\mathrm{H} 2}$. For a constant $\Phi$, two parameters change when increasing $\mathrm{X}_{\mathrm{H} 2}$ : the reactive species dilution, which decreases, and the temperature of the unreacted fuel/oxidizer mixture $\left(\mathrm{T}_{\text {mix }}\right)$, which increases due to the lower overall mole fraction of the cold $\mathrm{H}_{2} / \mathrm{N}_{2}$ blend.

In order to separate the influence of dilution and temperature, additional isothermal calculations were carried out for 15 bar with $T_{\text {cf }}=T_{\text {fuel }}=1173 \mathrm{~K}$. The results revealed that dilution has no influence on $\tau_{\mathrm{ign}}$ for $\mathrm{X}_{\mathrm{H} 2}>0.15$, which is relevant for the current study. This is reasonable since the majority of $\mathrm{N}_{2}$ originates from the crossflow, where $\mathrm{X}_{\mathrm{N} 2}$ is constant. Thus, the tendencies in Fig. 5 are mainly related to changes in $\mathrm{T}_{\text {mix. }}$

To visualize the influence of temperature, Fig. 6 shows $\tau_{\text {ign }}$ versus $T_{\text {mix }}$ for more detailed calculations in the range of $\Phi=0.001-0.5$ and $\mathrm{X}_{\mathrm{H} 2}=0.01-0.5$. For each pressure, the upper boundary corresponds to the lowest $\mathrm{X}_{\mathrm{H} 2}$, while the lower corresponds to $\mathrm{X}_{\mathrm{H} 2}=0.5$. Higher $\mathrm{T}_{\text {mix }}$ are related to lower $\Phi$, as discussed above.

The ignition delay times for 10 and 15 bar exceed those at 5 bar for about $\mathrm{T}_{\text {mix }}>1000 \mathrm{~K}$ $\left(\mathrm{X}_{\mathrm{H} 2}=0.5\right)$. This means that around $\mathrm{T}_{\text {mix }}=1000 \mathrm{~K}$ the system transitions from the first ignition limit for hydrogen, where $\tau_{\text {ign }}$ decreases with increasing pressure, to the second ignition limit, which leads to an opposite pressure dependence of $\tau_{\text {ign }}[5,12]$. The second limit is characterized by the competition of the chain branching reaction $\mathrm{H}+\mathrm{O}_{2} \leftrightarrow \mathrm{OH}+\mathrm{O}$ and chain terminating reaction $\mathrm{H}+\mathrm{O}_{2}(+\mathrm{M}) \leftrightarrow \mathrm{HO}_{2}(+\mathrm{M})$, which favors the stabilization of $\mathrm{HO}_{2}$ at higher pressures. Thus, at higher pressures, higher temperatures are necessary to destabilize the $\mathrm{HO}_{2}$ and allow for ignition.

At 5 bar, a $\tau_{\text {ign }}$ minimum is formed at $\mathrm{T}_{\text {mix }} \approx 1130 \mathrm{~K}$ for $\mathrm{X}_{\mathrm{H} 2}=0.5(\Phi=0.082)$. This originates from the competition of increasing $\mathrm{T}_{\text {mix }}$ leading to shorter $\tau_{\text {ign }}$, and the associated increasingly 
lean mixtures, since very lean mixtures considerably increase the ignition delay. At higher pressures (10 and 15 bar), the minimum ignition delay times are shifted to higher temperatures $\left(\mathrm{T}_{\text {mix }} \approx 1165 \mathrm{~K}\right.$ ). This is due to the higher pressures requiring higher temperatures to destabilize $\mathrm{HO}_{2}$. Thus, the promoting effect of increasing $\mathrm{T}_{\text {mix }}$ remains dominant compared to the delaying effect of very lean mixtures up to higher temperatures. However, the 10 and 15 bar minima are located at very lean mixture states $(\Phi \approx 0.02)$, which in total leads to longer $\tau_{\text {ign }}$ for 10 and 15 bar compared to 5 bar at their respective minima. This is in addition to the already reversed pressure dependence of $\tau_{\text {ign }}$ within the second ignition limit. No minimum for $\tau_{\text {ign }}$ is present for low $\mathrm{X}_{\mathrm{H} 2}$, since the high temperatures are reached only for very lean mixtures $(\Phi<0.02)$ due to the high dilution. Thus, the ignition promoting influence of the temperature on $\tau_{\text {ign }}$ is overwhelmed by the inhibiting effect of very lean mixtures.

\section{Discussion}

Comparing the experimental results to the simulations reveals that ignition of the JICFconfiguration does not necessarily follow the trends expected from the chemical kinetics simulations. One noticeable difference was found for the absolute values of ignition delay times. In Fig. 6, the range of the estimated critical experimental ignition delay times is indicated by the black lines. It is obvious that the shortest $\tau_{\text {exp,crit }}$ are considerably shorter than the minimum delay times in the homogeneous system, $\tau_{\text {ign }}$. The difference is particularly distinct for 10 and 15 bar, with $\tau_{\text {exp,crit }}$ up to an order of magnitude lower than $\tau_{\text {ign. }}$. It is noted that this discrepancy might be overestimated since $\tau_{\text {exp,crit }}$ presumably is underestimated, as explained above. However, even an underestimation of $\tau_{\text {exp,crit }}$ by a factor of 2-3 would not reconcile the discrepancy between the lowest experimental and chemical kinetic ignition delay times for 10 and 15 bar. The finding that ignition is facilitated in the turbulent system 
compared to the homogeneous one is in line with a study of Blouch and Law [9]. They related this to discrete turbulent mixing, which can combine parcels of high temperature gasses, reactants and radicals that would not have mixed without turbulence. While ignition was facilitated for lower turbulence levels, they found this effect to decrease with increasing turbulence intensities due to the reduced residence times at local conditions favoring ignition.

Another profound difference is observed in the pressure dependence. Far on the fuel lean side, where ignition is expected due to low ignition delay times, the simulated $\tau_{\text {ign }}$ decreased with pressure because of the dominant second limit pathways. Transferring this to the JICFconfiguration would mean that jet autoignition at lower pressures is expected at lower $\mathrm{X}_{\mathrm{H} 2}$. Further, the difference should be more pronounced between 5 and 10 bar than between 10 and 15 bar. However, no significant pressure dependence was observed in the JICF-configuration for Case $\mathrm{C}$ or between 5 and 10 bar for Cases A and B. This would correspond to ignition occurring in the temperature range at which the system is transitioning to the second limit, where ignition delay times are similar at all three pressures. In the homogeneous system this takes place at lower temperatures, i.e. higher ignition delay times. It was, however, reported that high strain rates can shift the transition from the first to the second limit towards higher temperatures by changing the residence time of radicals in an ignition kernel and thus affecting the dominant chemistry [5]. Hence, the temperature range of similar ignition delay times in the current, highly strained flow field might be shifted to the region of higher temperatures.

It also was found that the influence of pressure on ignition in the JICF depended on the bulk velocity. Ignition at Case $A\left(\mathrm{u}_{\mathrm{cf}}=300 \mathrm{~m} / \mathrm{s}\right)$ at 15 bar was at high $\mathrm{X}_{\mathrm{H} 2}$ compared to Case $\mathrm{C}\left(\mathrm{u}_{\mathrm{cf}}\right.$ $=200 \mathrm{~m} / \mathrm{s}$ ), but similar at 5 and 10 bar. This might be explained by the finding that the impact of turbulence also depends on the preferred reaction pathways [9], i.e. ignition limits, since the slower reaction pathways beyond the second limit are earlier affected by faster excursion 
times related to higher turbulence intensities. In particular, this means that turbulence can have rather promoting effect within the second ignition limit, while it can hinder ignition beyond the second limit. At higher pressures, the transition from the first to the second limit takes place at higher temperatures compared to lower pressures. Assuming that ignition in the experiment occurred close to the transition between the first and second limits, as explained above, the 15 bar conditions might be governed by the first limit pathway, while that of the second limit may be dominant at 5 and 10 bar. This could explain why the increased turbulent fluctuations due to the increased bulk velocity of Case A $\left(\mathrm{u}_{\mathrm{cf}}=300 \mathrm{~m} / \mathrm{s}\right)$ compared to Case C $\left(\mathrm{u}_{\mathrm{cf}}=200 \mathrm{~m} / \mathrm{s}\right)$ could have an inhibiting effect at 15 bar, which was not observed at 5 and 10 bar.

The different ranges of momentum flux ratios related to Mix1 and Mix2 did not significantly influence $\mathrm{X}_{\mathrm{H} 2 \text {,fs. }}$ This might suggest that the influence of changes in the flow field and mixing due to differences in momentum flux ratio are negligible for autoignition in the studied range, compared to the influence of the crossflow conditions. Only for Case B at 10 bar was a significant difference observed in $\mathrm{X}_{\mathrm{H} 2 \text {,fs }}$ between Mix1 (about 0.63) and Mix2 (about 0.46). Figure 5 suggests that, at these higher $\mathrm{X}_{\mathrm{H} 2}$, ignition characteristics become increasingly insensitive to changes in $\mathrm{X}_{\mathrm{H} 2}$; the ignition delay times for different $\mathrm{X}_{\mathrm{H} 2}$ are similar. This might suggest that, in this $\mathrm{X}_{\mathrm{H} 2}$ range, small changes in the flow field and mixing characteristics might become relatively more significant compared to further increasing $\mathrm{X}_{\mathrm{H} 2}$.

\section{Conclusions}

Autoignition of $\mathrm{H}_{2} / \mathrm{N}_{2}$ jets in crossflows of vitiated air has been studied at different pressures, crossflow temperatures, crossflow velocities, and jet penetration ranges. The results were compared to chemical kinetic simulations of homogeneous systems, which were conducted 
for an exemplary set of boundary conditions (p, T, composition of vitiated air) corresponding to the current experiments.

Both the experiments and simulations showed that lower temperatures inhibited ignition at all investigated pressures, which is expected since temperature is the dominant factor influencing the kinetic ignition delay time.

However, several differences were observed between the technically relevant jet-in-crossflow configuration and the homogeneous system. The ignition delay times estimated from the JICF-configuration were found to be considerably shorter than those from the kinetic simulations. Furthermore, no distinct influence of pressure on ignition was observed for the experimental test case at the lower crossflow velocity, while for the higher crossflow velocities, ignition was inhibited at 15 bar. In contrast, results from the homogeneous calculations that ignore the velocity suggested that ignition at 5 bar should be facilitated compared to 10 and 15 bar due to the transition to second limit reactions in the relevant temperature range.

The described findings suggest that the turbulent mixing and inhomogenous flow field in the JICF strongly influence the ignition behavior. Not only can they affect the absolute ignition delay time, but also pressure dependencies. Findings from previous studies of how strain and turbulence influence the ignition behavior can provide a reasonable explanation for the observed deviating tendencies, even though they might not encompass the entire range of parameters influencing autoignition in the highly inhomogeneous JICF-configuration.

\section{Acknowledgements}

The authors would also like to thank U. Prestel, D. Lebküchner, K. Ferst, S. Peukert and M. Kapernaum for their technical support during the measurements. 


\section{References}

[1] J. Fleck, P. Griebel, A.M. Steinberg, M. Stöhr, M. Aigner, A. Ciani, J. Eng. Gas Turb. Power 134 (2012) 041502 1-8.

[2] M. Yao, Z. Zheng, H. Liu, Prog. Energy Combust. Sci. 35 (2009) 398-437.

[3] J.D. Micka, J.F. Driscoll, Combust. Flame 159 (2012) 1205-1214.

[4] T. Lieuwen, V. McDonell, E. Petersen, D. Santavicca, J. Eng. Gas Turb. Power 130 (2008) 011506 1-10.

[5] T.G. Kreutz, C.K. Law, Combust. Flame 104 (1996) 157-175.

[6] E. Martorakos, T.A. Baritaud, T.J. Poinsot, Combust. Flame 109 (1997) 198-223.

[7] E. Mastorakos, Prog. Energy Combust. Sci. 35 (2009) 57-97.

[8] C.G. Fotache, T. Kreutz, D.L. Zhu, C.K. Law, Combust. Sci. Tech. 109 (1995) 373393.

[9] J.D. Blouch, C.K. Law, Combust. Flame 132 (2003) 512-522.

[10] C.N. Markides, E. Mastorakos, Proc. Combust. Inst. 30 (2005) 883-891.

[11] L. von Elbe, Combustion, Flames and Explosions of Gases, Academic Press Inc. Ltd., London, 1961.

[12] J. Herzler, C. Naumann, Proc. Combust. Inst. 32 (1) (2009) 213-220.

[13] A.R. Karagozian, Prog. Energy Combust. Sci. 36 (2010) 531-553.

[14] T.F. Fric, A. Roshko, J. Fluid Mech. 279 (1994) 1-47.

[15] S.H. Smith, M.G. Mungal, J. Fluid Mech. 357 (1998) 83-122.

[16] A.M. Steinberg, R. Sadanandan, C. Dem, P. Kutne, W. Meier, Proc. Combust. Inst. (2012) Submitted. 
[17] F. Joos, P. Brunner, B. Schulte-Werning, K. Syed, A. Eroglu, ASME, 1996-GT-315 (1996) 1-11.

[18] F. Güthe, J. Hellat, P. Flohr, J. Eng. Gas Turb. Power 131 (2009) 021503 1-7.

[19] J.M. Fleck, P. Griebel, A.M. Steinberg, M. Stöhr, M. Aigner, A. Ciani, ASME, GT2010-22722 (2010) 1-10.

[20] R. Lückerath, W. Meier, M. Aigner, J. Eng. Gas Turbines Power 130 (2008) 011505 $1-7$.

[21] M. Mörtberg, W. Blasiak, A.K. Gupta, J. Eng. Gas Turbines Power 129 (2007) 556564.

[22] J. Li, Z. Zhao, A. Kazakov, F.L. Dryer, Int. J. Chem Kin. 36 (2004) 566-575.

[23] A. Keromnes, N. Donohoe, H. Curran, J. Herzler, C. Naumann, P. Griebel, IGTI conference, 86, Brussels, Belgium, 2010.

[24] E. Hasselbrink, M. G. Mungal, J. Fluid Mech. 443 (2001) 1-25.

[25] A. Rivero, J.A. Ferré, F. Giralt, J. Fluid Mech. 444 (2001) 117-149. 


\section{Tables}

Table 1 Composition (mole fraction) of the vitiated air crossflow.

\begin{tabular}{|c|c|c|c|c|}
\hline & $\mathbf{X}_{\mathbf{O} 2}$ & $\mathbf{X}_{\mathbf{N 2}}$ & $\mathbf{X}_{\mathbf{C O 2}}$ & $\mathbf{X}_{\mathbf{H 2 0}}$ \\
\hline \hline $\max \mathrm{O}_{2}$ & 0.15 & 0.769 & 0.27 & 0.54 \\
\hline $\min \mathrm{O}_{2}$ & 0.145 & 0.765 & 0.31 & 0.59 \\
\hline
\end{tabular}

Table 2 Inflow conditions of the vitiated air crossflow.

\begin{tabular}{|c|c|c|c|c|}
\hline $\begin{array}{c}\text { Test } \\
\text { Case }\end{array}$ & $\begin{array}{c}\mathbf{p} \\
{[\mathbf{b a r}]}\end{array}$ & $\begin{array}{c}\mathbf{T}_{\mathbf{c f}} \\
{[\mathbf{K}]}\end{array}$ & $\begin{array}{c}\mathbf{u}_{\mathbf{c f}} \\
{[\mathbf{m} / \mathbf{s}]}\end{array}$ & $\mathbf{R e}_{\mathbf{c f}} \mathbf{1 1 0}^{\mathbf{5}}$ \\
\hline \hline $\mathbf{A}$ & $5 / 10 / 15$ & 1185 & 300 & $2.3 / 4.5 / 6.0$ \\
\hline $\mathbf{B}$ & $5 / 10 / 15$ & 1143 & 300 & $2.4 / 4.8 / 6.4$ \\
\hline $\mathbf{C}$ & $5 / 10 / 15$ & 1185 & 200 & $1.5 / 3.0 / 4.0$ \\
\hline
\end{tabular}

Table 3 Mean $\mathrm{H}_{2}$ content in the jet $\mathrm{X}_{\mathrm{H} 2 \text {,fs }}$ and momentum flux ratio $\mathrm{J}$ at autoignition leading to flame stabilization.

\begin{tabular}{|c|c|c|c|c|}
\hline $\begin{array}{l}\text { Test } \\
\text { case }\end{array}$ & $\mathrm{X}_{\mathrm{H} 2, \mathrm{fs}}$ & $\mathbf{J}$ & $\mathrm{X}_{\mathrm{H} 2 \text {,fs }}$ & $\mathbf{J}$ \\
\hline & \multicolumn{2}{|c|}{ Mix1 } & \multicolumn{2}{|c|}{ Mix2 } \\
\hline A5 & 0.32 & 1.1 & 0.26 & 2.6 \\
\hline A10 & 0.30 & 1.2 & 0.27 & 2.9 \\
\hline A15 & 0.49 & 1.8 & 0.50 & 4.5 \\
\hline B5 & 0.52 & 1.7 & 0.46 & 4.0 \\
\hline B10 & 0.62 & 2.3 & 0.47 & 4.3 \\
\hline B15 & \multicolumn{4}{|c|}{ No flame-stabilizing autoignition } \\
\hline $\mathrm{C5}$ & 0.26 & 1.0 & 0.21 & 2.4 \\
\hline C10 & 0.27 & 1.1 & 0.24 & 2.7 \\
\hline $\mathrm{C} 15$ & 0.25 & 1.1 & 0.24 & 2.9 \\
\hline
\end{tabular}




\section{Figures}

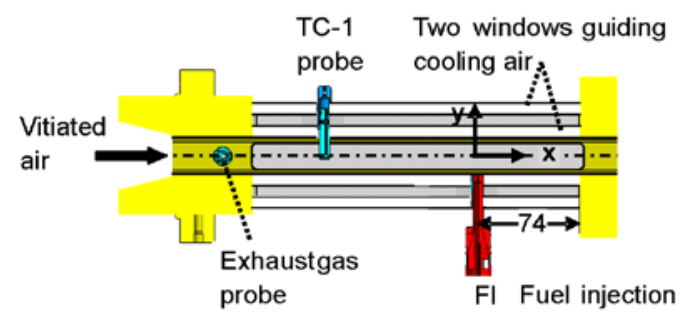

Figure 1 JICF test-section.

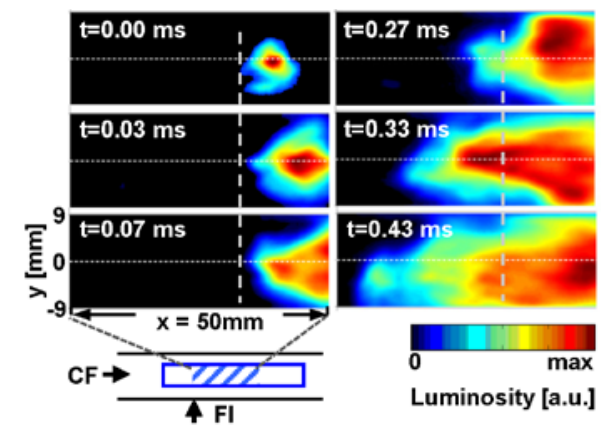

Figure 2 Development of an exemplary flame-stabilizing ignition event (Case A15, Mix2).

Dashed line marks the position at which the kernel first occurred ( $\mathrm{x}=33 \mathrm{~mm}$; defined as $\mathrm{t}=0.00 \mathrm{~ms}$ ). 


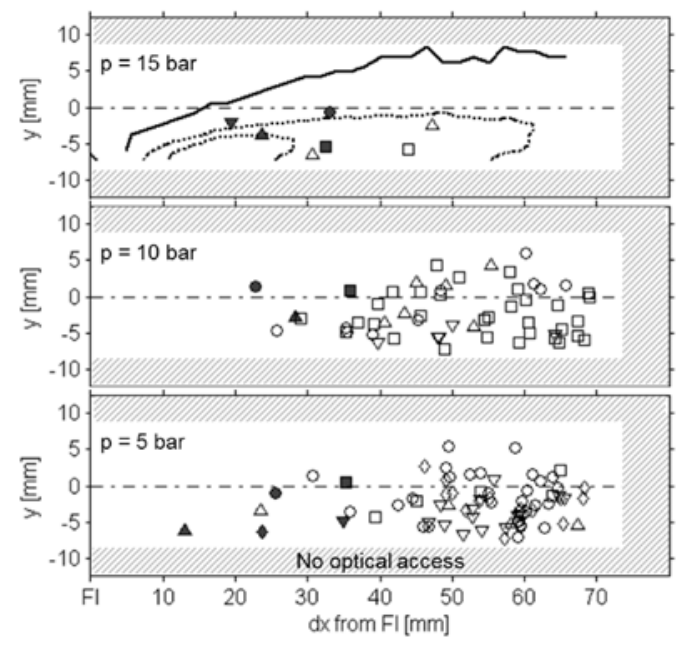

Figure 3 Spatial distribution of initial ignition kernel locations for the pressure variation of Case A, Mix2. Each different symbol shape at a given condition represents a different repetition at that condition. Open symbols: Kernels that convected out of the duct. Closed symbols: Kernels leading to flame stabilization. For $\mathrm{p}=15 \mathrm{bar}$, velocity iso-contours from an exemplary measured flow field with $\mathrm{J}=3.5$ is overlaid (Dotted lines: $\mathrm{u}_{\mathrm{x}} / \mathrm{u}_{\mathrm{cf}}$ - iso-contours at $\mathrm{u}_{\mathrm{x}} / \mathrm{u}_{\mathrm{cf}}=1 / 2$ and $3 / 4$, solid line: jet trajectory (maximum velocity).

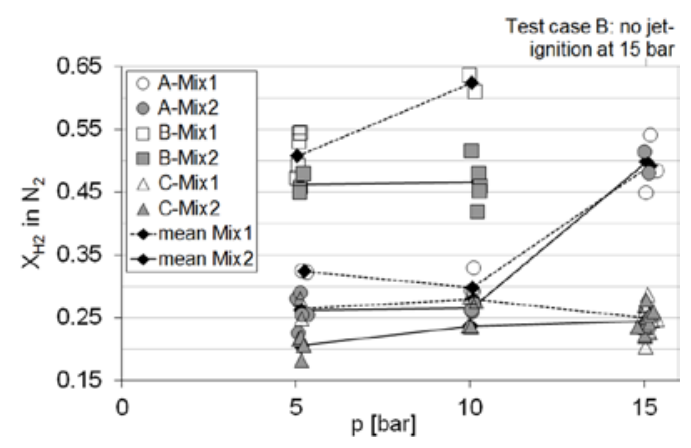

Figure $4 \mathrm{X}_{\mathrm{H} 2}$ in the jet at autoignition leading to flame stabilization versus the pressure. 


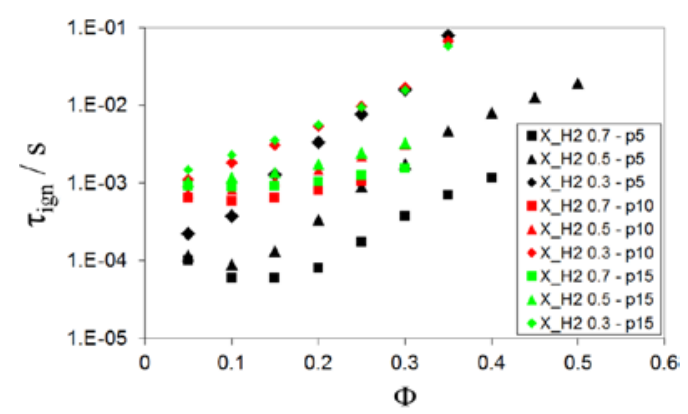

Figure 5 Ignition delay times based on chemical kinetics simulations of homogeneous systems versus $\Phi$.

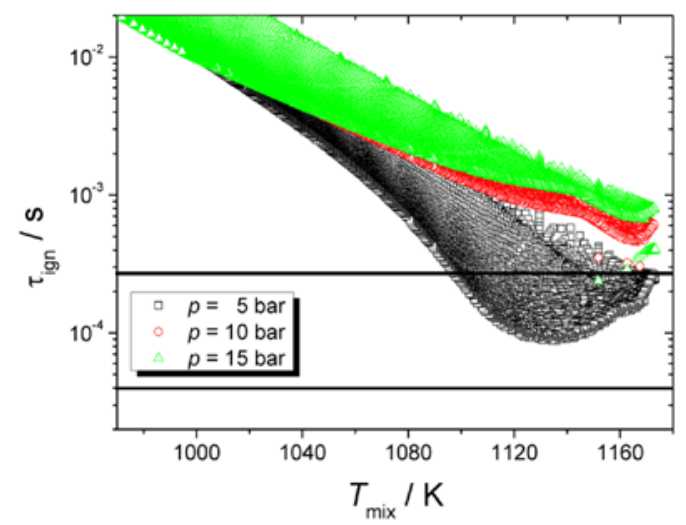

Figure 6 Ignition delay times from chemical kinetics simulations of homogeneous systems versus the fuel-oxidizer mixture temperature. Black lines indicate the range of experimentally measured ignition delay times. 